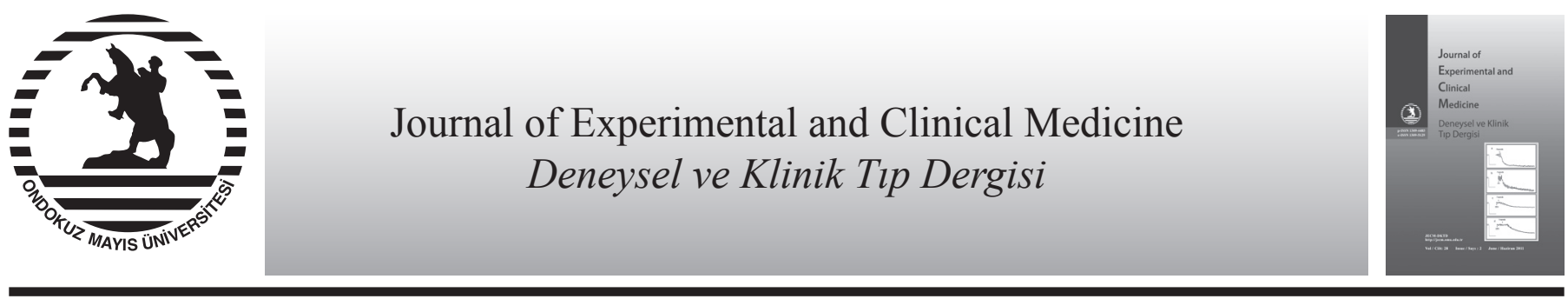

Derleme / Review

\title{
Entübasyonda videolaringoskopi
}

\author{
Videolaryngoscopy for intubation
}

Fatih Özkan

Ondokuz Mayıs Üniversitesi, Tip Fakültesi, Anesteziyoloji ve Reanimasyon AD, Samsun

\begin{tabular}{|c|c|}
\hline \multicolumn{2}{|c|}{ MAKALE BİLGÍLERİ } \\
\hline \multicolumn{2}{|c|}{ Makale geçmişi } \\
\hline Geliş & $13 / 01 / 2011$ \\
\hline Kabul & 15 / 02 / 2011 \\
\hline
\end{tabular}

\section{* Yazıșma Adresi:}

Fatih Özkan

Ondokuz Mayıs Üniversitesi

Tıp Fakültesi Anesteziyoloji ve

Reanimasyon AD, Samsun

e-posta: dr.fat.oz@hotmail.com

\section{Anahtar Kelimeler: \\ Hava yolu cihazı \\ Fiberoptik teknoloji \\ Zor hava yolu \\ Entübasyon \\ Laringoskop \\ Laringoskopi}

\section{Keywords:}

Airway device

Fiberoptic technology

Diffucult airway

İntubation

Laryngoscope

Laryngoscopy

\section{ÖZET}

Video teknolojisi ve fiberoptik sistemlerdeki son gelişmeler videolaringoskoplar gibi yeni entübasyon araçlarının ve teknolojilerinin gelişmesiyle sonuçlanmıştır. Videolaringoskoplar, blade'inin uç kısmına yerleştirilmiş bir optik sistem aracılı̆̆ıyla indirekt bir görüşe izin verdiği için entübasyon ve laringoskopide farklı bir yaklaşım olarak kabul edilirler. Bu çalışmanın amacı konvansiyonel direkt laringoskopi ile entübasyonu güç ya da olanaksız olan hastalarda videolaringoskopinin klinik kullanımdaki rolünü tanımlamak için son yıllarda basılan materyalleri derlemektir. Yazarlar yeni laringoskoplar ve videolaringoskoplar gibi cihazlar ile farklı ve zor koşullar altında uygulanan direkt ve indirekt laringoskopileri karşılaştırmışlardır. Sonuçlar, gerçek zor entübasyon olgularının az olması ve seçilen hasta popülasyonunun yüksek heterojenitesinden dolayı toplanan verilerin çoğunun yetersiz olduğunu göstermiştir. Diğer taraftan entübasyon başarısından çok görüntüyü değerlendirmenin yeni cihazların sonuçlarıyla ilgili şüphelere neden olacağ açıktır. Yeni laringoskopun ya da videolaringoskopun primer rolü konvansiyonel yöntemlerle zor hatta olanaksız olan entübasyonda daha iyi bir performans elde etmek olmalıdır. Bu cihazların klinik rolü zor hava yolu çalışmaları ile desteklenmeyi beklemektedir.

J. Exp. Clin. Med., 2011; 28:39-44

\begin{abstract}
Recent advances in fiberoptic systems and video technology have resulted in the development of new intubation devices and techniques such as videolaryngoscopes. Videolaryngoscopes have adopted a different approach to laryngoscopy and intubation because of the indirect view allowed by an optical system positioned near the tip of the blade. The aim of this article is to review material published in recent years for describe the clinical use of videolaryngoscopes in a patient who had been difficult or impossible to intubate by conventional direct laryngoscopy. The authors compare direct and indirect laryngoscopies performed under different conditions of difficulty through the instruments such as new laryngoscopes or videolaryngoscopes. The conclusions have indicated that much of the collected data were inadequate because of the high heterogeneity of the selected populations and the small number of really difficult-to-intubate patients. Otherwise, it is clear that reporting the change of view rather than the rate of success at intubation is likely to bias the results towards the new devices. The primary role of a new laryngoscope or videolaryngoscope should be to enable better performance in patients who are difficult or even impossible to intubate using the conventional methods. The clinical role of these devices await confirmation in a large series of difficult airway surveys.

J. Exp. Clin. Med., 2011; 28:39-44
\end{abstract}

\section{Giriş}

Endotrakeal entübasyon, solunum yolunu güvenlik altına almak veya solunumu kontrol etmek amaciyla trakea içine bir tüp yerleştirilmesidir. Günümüzde genel anestezi uygulama- larının büyük bir kısmında rutin olarak kullanılan oral endotrakeal entübasyonun geçmişi genel anestezinin kendisinden daha eskidir. Endotrakeal entübasyon 18. yüzyıl sonlarında suda boğulanların resüsitasyonunda kullanılmaktaydı. Entü- 
basyon ilk kez 1792'de Curry tarafından taktil yöntemle gerçekleştirilmiştir. Anestezi uygulamak amacıyla ilk kez 1878'de Glasgow'lu bir cerrah olan William MacEwan parmaklarını kılavuz olarak kullanarak uyanık bir hastada ağız yoluyla trakeaya tüp yerleştirmiştir. Laringoskop yardımı ile entübasyon ise ilk kez Kirstein tarafindan (1895) uygulanmıştır. Laringoskobun bulunmasından sonra yirminci yüzyılın başlarından itibaren anesteziyolojideki bilimsel ve teknik ilerlemeler hasta üzerinde kullanımındaki becerilerin gelişmesini sağlamıștır (Burkle, 2004; Cooper, 2004). Yaklaşık 70 y1l önce Robert Macintosh endotrakeal tüpün larenksten geçişi sırasında görülen zorlukları azaltan yeni bir laringoskop kullanmıştır (Macintosh, 1943). Bu laringoskop anestezi tarihindeki en önemli ve başarılı cihazlardan biri olup son y1llara kadar milyonlarca üretildi (Jephcott, 1984). Devam eden teknik ve bilimsel gelişmeler fiberoptik yapıların, LED 1şıklarının, şarj edilebilir pillerin ve modifiye blade'lerin yardımıyla bu cihazın gelişmesine katkı sağladı. Bu gelişmeleri, blade'in ucuna yerleştirilmiş ve pozisyon verilebilen bir optik sistem yardımıyla indirekt görüşe ve farklı bir laringoskopik yaklaşıma izin veren laringoskopların ve videolaringoskop (VL)'ların kullanımı izledi. Bu cihazların gelişimi asıl olarak normalin dışında zor entübasyon beklenen hastaların entübasyonunun sağlanması amacını taşımaktadır.

Zor entübasyonun ve zor ventilasyonun önceden tahmin edilememesi ve yeterli hazırlığın yapılmaması hayatı tehdit eden sonuçlara neden olabilir (Jacob ve ark., 2009). Her anestezistin zor hava yolu ile baş etmek üzere önceden düşünülmüş ve hazırlanmış bir stratejik planı olmalıdır. Bu stratejiler bir araya getirilerek zor hava yolu algoritmaları oluşturulmalıdır. Hava yolu açıklığının sağlanmasında karşılaşılan yetersiz ventilasyon ve zor entübasyon gibi sorunlar genel anestezide karşılaşılan komplikasyonların önemli bir kısmını oluşturur. Klasik laringoskopi ile endotrakeal entübasyon deneme sayısı arttıkça komplikasyonların da önemli derecede arttığı gösterilmiş ve ASA (American Society of Anesthesiologists) tarafindan zor hava yolunda aynı yöntemde ısrarcı olmayıp, alternatif tekniklerin kullanımı önerilmiştir (Keaveny ve Knell, 1988). Ayrıca endotrakeal entübasyon ve tekrarlayan denemelerle birlikte taşikardi, kan basıncında yükselme, intrakraniyal basınçta artma, göz içi basıncı artışı gibi fizyopatolojik etkiler görülebilmektedir (Mallick ve ark., 1996). Sağlıklı insanlarda bu yanıtlar genellikle iyi tolere edilebilirken, sınırlı koroner veya miyokard rezervi olan hastalarda ise miyokardiyal iskemi veya yetersizliğe neden olabilir (Stone ve Gal, 2000).

$\mathrm{Bu}$ sıkıntıları azaltma girişimleri alternatif yöntemlerin araştırılmasına neden olmuştur. Günümüz şartlarında birçok cihaz ve teknik sayesinde zor havayolunun üstesinden gelmek kolaylaşmıştır. Bu nedenle birden çok tekniğe hakim olmak başarı şansını arttırır. Unutulmamalıdır ki acil durumlarda anestezist, en tecrübeli olduğu, kendisine en tanıdık gelen yöntemi seçmeli ve gerektiğinde yardım çağırmaktan çekinmemelidir.

Entübasyon zorluğu düşündüğümüz hastalarda kullanılabilecek yöntemlerden birisi olan VL şu an ve gelecekteki rolü ile ilgili olarak anestezistler arasında büyüyen bir tartışma vardır. $\mathrm{Bu}$ yöntem, anatomik yapıların gelişmiş görüntülenmesi, geniş ve net video ekranı, eğitici ve öğrenici arasındaki çabuk etkileşim olanağ1 ve olağanüstü bir öğrenim aracı olması gibi özellikleri nedeniyle geniş yankı uyandırmıştır (Merli, 2010). Ayrıca oral kavite, farinks ve larenks eksenleri- nin aynı hizaya getirilmeden laringoskopinin gerçekleştirilebilmesi ve endotrakeal entübasyona olanak tanıması servikal omurga anomalileri ve zor hava yolu hastalarında üstünlük sağlamakta, daha az komplikasyon anlamına gelmektedir. Bu durum, anestezistlere artık Macintosh laringoskopların bırakılması zamanının geldiğini ve yerini daha etkin yeni cihazlara bırakabileceğini düşündürmektedir (Merli, 2010).

VL'nin gelişimi, standart laringoskop blade'ini içeren endoskopik sistemin birleştirilmesi esasına dayanmaktadır. Günümüzde değişik firmalar tarafindan zor entübasyonlarda kullanılmak üzere üretilmiş VL sistemleri (Pentax-AWS video-laringoskop, Truview EVO2, GlideScope, Storz V-Mac, McGrath video-laringoskop gibi) geliştirilmiştir. Bu sistemlerde kamera ergonometrik olarak tasarlanmış handle ile birleştirilmiştir. Böylece anatomik yapılar monitor üzerinde büyütülmüş olarak görülebilir ve görüntü alanı artırılabilir. VL, tamamen vizüel kontrol altında rutin alıştırma ve öğrenmek için iyi bir çözüm olarak görülmektedir. VL'un şekli görüntüyü hava yolunun genişlemiş video imajını kullanarak mükemmelleştirir. Yüksek çözünürlüklü imajlar ve 1şık demetleri handle'da bütünleştirilerek video monitöre yansitılan hava yolu yapılarının video imajları modifiye edebilir. Kamera modifiye handle içine basit ve hızlı bir şekilde katılmıştır. Kamera aynı zamanda fiberoptik entübasyonda da kullanılabilir (Şek. 1).

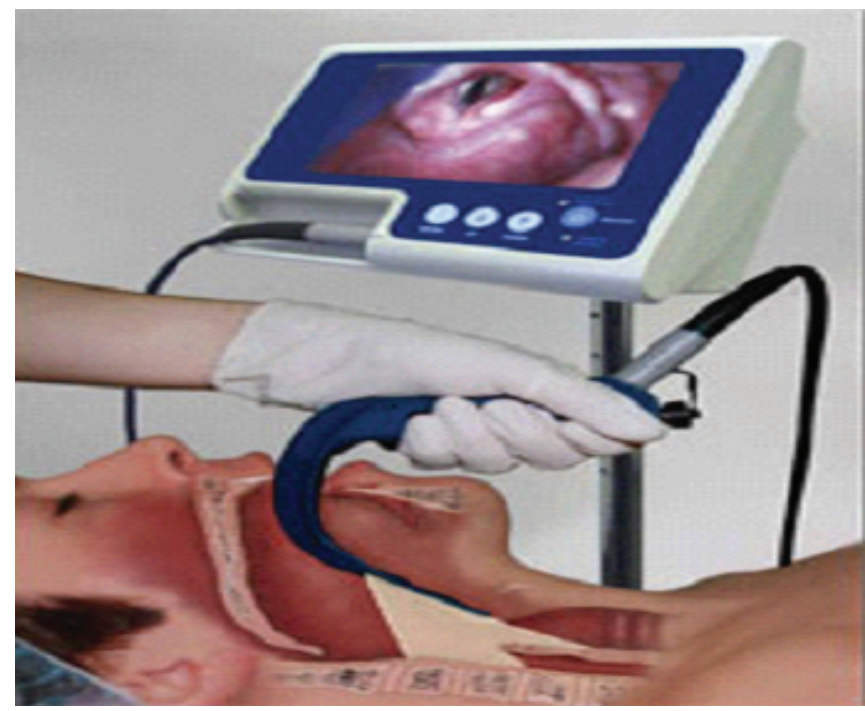

Şek. 1. Videolaringoskopi ve videolaringoskopi yardımıyla elde edilen edilen laringeal yapıların görüntüsü.

Video imajları direkt laringoskopiye göre birkaç farklı avantaja sahiptir. Sistem daha iyi görsel kontrol için video monitor üzerinde genişletilebilen açık video görüntülerini üretir. Eğer larinks maniplasyonu gerekirse, anestezist ve asistan monitördeki görüntü yardımıyla hareketlerinin koordinasyonunu sağlayıp laringeal yapıların görüntüsünü düzeltebilir (Hagberg ve ark., 2005). Orofarinksten trakeaya ETT ilerletildiği zaman laringeal yapıların görüntülenebilmesi laringoskop bladenin en distalinden yansıyan video imajları ile sağlanır (Kaplan ve ark., 2002a; Kaplan ve ark., 2006). VL sadece ETT değil, tam bir vizuel kontrol altında çift lümenli tüpün yerleştirileceği torasik vakalarda da kullanışlı olabilir (Kaplan ve ark., 2002b).

VL ile ilgili olarak literatür incelendiğinde özellikle son 10 yılda artan sayıda çalışmayla karşılaşılmaktadır. Bu çalışmada VL'nin diğer yöntemlerle karşılaştırıldığı çalışmalardan 
görüntü kalitesi, entübasyon süresi ve başarısı, hemodinamiye olan etkileri ve oluşan komplikasyonlar gibi özellikleri aşağıda irdelenmiştir.

\section{Videolaringoskopinin görüntü kalitesine etkisi}

VL'nin görüntü kalitesine etkisini irdeleyen çok sayıda çalışma mevcuttur. Bu çalışmalardan birinde Macnair ve ark., (2009) tarafından çocuklarda hava yolunu sağlamada VL ve direkt laringoskopi (DL) ile elde edilen C-L (CormackLehanne) skoru ve VL görüntü skorları karşılaştırılmış 30 hastada önce DL ile C-L skoru değerlendirilmiş sonra VL ile entübe edilmiş, 30 hastada ise tam tersi önce VL ile endoskopik görüntü değerlendirilmesi yapılmış, sonrasında DL ile entübe edilmiştir. DL'de C-L skoru grade I olan 11 hastanın 8'i VL'de grade I olarak değerlendirilmiş, grade III olarak değerlendirilen bir hasta ise grade II olarak değerlendirilmiş, 3 hasta ise her iki değerlendirmede grade II olarak değerlendirilmiştir. VL'de grade II görülen bir hastada ise DL ile grade I olarak değerlendirilmiş. VL ile 56 hastada elde edilen görüntü grade I olarak değerlendirilmiş, DL ile ise 48 hastada grade I görüntü elde edilmiştir. VL ile entübe edilen 30 hastanın 4 tanesinde ikinci denemeye ihtiyaç duyulmuş, 1 'i entübe edilemeyip DL ile entübe edilmiştir. Sun ve ark.'da 200 elektif cerrahi olgusunda yaptıkları araştırmada Macintosh blade'li laringoskopa göre VL ile glottik görüntünün daha iyi elde edildiğini belirtmişlerdir (Sun ve ark., 2005). Hackell ve ark. daha önce trakeo-özefagial fistül nedeni ile opere edilmiş ve entübasyon esnasında C-L skoru grade III olarak değerlendirilip zor entübe edilen küçük çene ve kısa boynu olan CHARCE sendromlu 4 aylık bir hastada miringotomi operasyonu için VL ile entübasyon denemişlerdir (Hackell ve ark., 2009). Bu hastada VL ile Grade I görüntü elde edildiğini ve ilk denemede entübasyonun gerçekleştirildiğini bildirmişlerdir. Aynı çalışmada küçük çene, kısa boyun ve büyük dili olan trizomi 18 kromozomal bozukluğu tanısı almış dokuz aylık başka bir hastada ise DL ile grade III olan görüntüyü VL'de grade I olarak değerlendirdiklerini belirtmişlerdir (Hackell ve ark., 2009). Konstantinos ve ark. zor entübasyon bekledikleri hastalarda VL ve Macintosh blade ile elde ettikleri glottik görüntüyü karşılaştırmışlar ve benzer sonuca varmışlardır (Konstantinos ve ark., 2009). Van Zundert ve ark. elektif cerrahiye alınacak 450 hastayı 150'şerli 3 gruba ayırıp DL ile görüntünün yanı sıra 3 farklı VL çeşidini karşılaştırmışlar ve üç farklı VL yöntemiyle de C-L skorunu DL'ye göre daha iyi bulduklarını vurgulamışlardır (Van Zundert ve ark., 2009). Enomoto ve ark. zor entübasyon ile ilgili yaptıkları bir çalışmada, VL ile Macintosh blade'li laringoskopu boyun stabilizasyonu nedeni gereken, boyun ekstansiyonu kısıtlanmış 203 hastada kullanmışlar ve glottik görüntü açısından değerlendirmişlerdir (Enomoto ve ark., 2008). Bu çalışmada VL Grubu'nda tüm görüntüler C-L grade I, Macintosh Grubu'nda 21 hastanın görüntüsü C-L grade III olarak değerlendirilmiştir. Malik ve ark.'nın yaptığ benzer sonuçlara ulaşılmıştır (Malik ve ark., 2008). Miceli ve ark. 12 anestezi uzmanına maket üzerinde havayolu ile ilgili 3 senaryo (normal havayolu, kısitlı boyun ekstansiyonu, ödemli dil) hazırlamışlar, Macintosh blade'li laringoskopiye göre VL ile elde ettikleri glottik görüntünün daha iyi olduğunu vurgulamışlardır (Miceli ve ark., 2008). Bu sonuçlar; glottik görüntülemenin C-L skorlaması ile değerlendirilmesi konusunda, videolaringoskopun Macintosh blade'li laringoskopa göre çok daha başarılı olduğunu göstermektedir.
3. Videolaringoskopinin entübasyon başarısına etkisi

VL ile ilgili yapılan çalışmalarda VL'nin entübasyon başarısına olan etkisi literatürde ayrıntılı olarak tartışılmıştır. Bu çalışmalardan birinde Cavus ve ark. VL'nin anestezi indüksiyonu sırasında entübasyon başarısını incelemişler ve 60 hastanın hepsinde glottik görüntünün ilk denemede elde edildiğini, entübasyonun 52 hastada ilk denemede, 6 hastada 2. denemede, 2 hastada ise 3 . denemede geçekleşebildiğini bildirmişlerdir (Cavus ve ark., 2010). Zor ya da başarısız entübasyon hikayesi olan 18 çocuk hastada VL'yi konvansiyonel DL ile karşılaştıran bir çalışmada ise VL'nin laringoskopik görüntüyü DL'ye göre önemli ölçüde iyileştirdiği vurgulanmıştır (Armstrong ve ark., 2010). Pediatrik ileri yaşam desteği kursu almış ancak VL eğitimi almamış pediatri stajiyerleriyle yapılan ve Macintosh laringoskopi ile VL'yi karşılaştıran diğer bir çalışmada mankenler üzerinde 4 senaryo denenmiştir (Rodriguez-Nunez ve ark., 2010). Bu çalışmada normal ya da zor hava yolu simulasyonu oluşturulmuş manken modellerinde stajyerlerin Macintosh ile karşılaştırıldığında VL ile entübasyonda daha başarılı olmadığı, bu becerilerinin geliştirilmesi için spesifik eğitim programlarının gerekliliği vurgulanmıştır. Entübasyon deneyimi olmayan 45 tıp ve hemşirelik öğrencisinin yenidoğan mankeni üzerinde VL ve DL ile yaptıkları entübasyon denemelerinin başarısını araştıran bir çalışmada, iki yöntem arasında başarılı entübasyon için gerekli girişim sayıları arasında fark olmadığı ancak VL ile entübasyonda, entübasyon için gerekli sürenin daha uzun olduğu belirtilmiştir (Iacovidou ve ark., 2010). Dhonneur ve ark., morbid obez 318 hasta üzerinde yaptıkları çalışmada LMA CTrach, Airtraq Video-Laringoskop ve konvansiyonel Macintosh laringoskopu karşılaştırmışlardır (Dhonneur ve ark., 2009). LMA CTrach ve Airtraq ile \%100 entübasyon başarısı sağlamışlar, bir hastada Macintosh laringoskop ile entübasyon yapamayı LMA CTrach ile entübe etmişlerdir. Oksijenlenmenin Airtraq ve LMA CTrach grubunda Macintosh'a göre daha iyi olduğunu bildirmişlerdir. Van Zundert ve ark. elektif cerrahiye alınacak 450 hastay 150 'şerli 3 gruba ayırıp DL ile görüntünün yanı sıra 3 farklı VL çeşidini karşılaştırmışlardır (Van Zundert ve ark., 2009). GlideScope ranger'de 64 hastada entübasyon için stileye ihtiyaç duyulmuş, bunların da 49'u ilk denemede, 15'i ikinci ve üçüncü denemede entübe edilmiştir. Mc Grath series- 5 marka VL ile 88 hastada stileye ihtiyaç duyulmuş ve bunların 65'i ilk, 23'ü ikinci denemede entübe edilmiştir. Storz VMac VL ile 10 hastada stileye ihtiyaç duyulmuş, bunların 8'i ilk, 2'si ikinci denemede entübe edilebilmiştir. Maruyama ve ark. ise elektif cerrahi planlanan 13 hastada VL ve Macintosh blade'li laringoskop ile yapılan entübasyonlarda entübasyon başarı oranını karşılaştırdıklarında, iki laringoskop arasında anlamlı fark bulamamışlardır (Maruyama ve ark., 2008). Bu çalışmada daha önce yapılan birçok çalışmanın aksine, ekstansiyonu kısıtlı zor entübasyon vakaları için alternatif olarak üretilen VL'de daha fazla ekstansiyona gerek duyulmuştur. Narang ve ark. manken üzerinde üç havayolu senaryosunda (standart, azalmış boyun ekstansiyonu, ödemli dil), VL ile Macintosh blade'li laringoskopu entübasyon başarısı yönünden karşılaştırmışlar ve sonuçta başarı oranını sırasıyla \%83 ve \%23 bulmuşlardır (Narang ve ark., 2009). Enomoto ve ark. yaptıkları bir çalışmada VL ile yapılan 99 entübasyonun hepsini başarılı kabul ederken, Macintosh Grubu'ndaki 104 entübasyondan 93'ünü başarılı kabul etmişlerdir (Enomoto ve ark., 2008). Sonuçta VL'nin entübasyon için iyi koşullar 
ve iyi glottik görüntü sağladığı, ancak bunun kolay ve başarılı trakeal tüp yerleştirilmesini garanti edemeyeceği görülmektedir.

\section{Videolaringoskopinin entübasyon süresine etkisi}

Miceli ve ark., entübasyon süresini karşılaştırdıkları bir çalışmada Macintosh blade'li laringoskop ile VL'u karşılaştırmışlardır. Her anestezi uzmanına her bir senaryo için entübasyonu 10'ar defa tekrarlatmışlar ve entübasyon süresinin VL ile uzadığını belirtmişlerdir (Miceli ve ark., 2008). Bensghir ve ark. elektif torasik cerrahi için çift lümenli tüp yerleştirilecek 68 hastada VL ile DL ile gerekli entübasyon sürelerini karşılaştırmışlar ve VL'nin entübasyon için gerekli zamanı azalttığını ileri sürmüşlerdir (Bengshir ve ark., 2010). Dhonneur ve ark. morbid obez 318 hasta üzerinde yaptıkları çalışmada LMA CTrach, Airtraq video-laringoskop ve konvansiyonel Macintosh laringoskopu karşılaştırmışlardır. Entübasyon süreleri Airtraq, Macintosh ve LMA CTrach sirası ile 29, 69 ve 109 sn olarak bulunmuştur (Dhonneur ve ark., 2009). Shimada ve ark. anestezist olmayan kişiler tarafindan yapılan ve nazotrakeal entübasyonlarda VL ile Macintosh laringoskopiyi karşılaştırdıkları bir çalışmada, VL ile daha kısa sürede hava yolunun güvence altına alındığını vurgulamışlardır (Shimada ve ark., 2010). VL ile yapılan entübasyonların hiçbirinde magill forseps gerekmezken Macintosh laringoskop kullanımında hastaların \%75'inde magill forseps gerekmiştir. Macnair ve ark. VL ve DL'yi karşılaştırdıkları 2-16 yaş grubu 60 çocuk üzerinde yapılan bir çalışmada ortalama entübasyon süresini DL ile 12 sn, VL ile 22,5 sn bulmuşlardır (Macnair ve ark., 2009). Malik ve ark., genel anestezi altında trakeal entübasyon uygulanacak boyun ekstansiyonu kisitlı 120 hastada Macintosh blade'li Truview EVO2, GlideScope ve Airwayscope (AWS) laringoskoplarını kullanmışlar ve entübasyon kalitesi ile entübasyon süresi yönünden grupları karşılaştırmışlardır. GlideScope ve AWS laringoskoplar ile yapılan entübasyonlar daha uzun sürede yapılırken, Macintosh blade'li Truview EVO2 laringoskopları ile daha kısa sürede ve daha kolay entübasyon sağlamışlardır (Malik ve ark., 2008). Elektif cerrahiye alınacak 450 hastada 3 farklı VL çeşidinin entübasyon sürelerini karşılaştıran bir çalışmada, GlideScope ranger ile entübasyon süresi $34 \pm 20$ sn, Storz VMac ile $18 \pm 12$ sn ve Mc Grath series- 5 ile de $38 \pm 23$ sn olarak bulunmuştur (Van Zundert ve ark., 2009). Aynı zamanda Storz V- Mac'da hastaların \%7'sinde stile kullanılırken diğerlerinin \%50'sinde stile kullanılmış, Storz V-Mac' da entübasyon süresinin daha kısa ve entübasyonun daha kolay olduğu nu belirtilmiştir. Sun ve ark., da benzer olarak 200 elektif cerrahi planlanan hastay1 VL veya Macintosh blade'li laringoskop ile entübe etmişler ve entübasyon süresini Macintosh Grubu'nda 30sn, VL Grubu'nda 46sn olarak tespit etmişlerdir (Sun ve ark., 2005). VL ile entübasyon için gereken sürenin uzadığını fakat zor entübasyon için avantajlarının olabileceğini savunmuşlardır. Vlaten ve ark. dört yaş ve altı 56 çocukta entübasyon için standart DL ile VL'yi karşılaştırmışlardır (Vlaten ve ark., 2009). En iyi görüntülenme zamanı DL'de ortalama 5,5sn iken VL'de 7sn, entübasyon zamanı DL'de $21 \mathrm{sn}$ iken VL'de $27 \mathrm{sn}$, glottik açıklık yüzdesi DL'de \%97.5, VL'de $\% 100$ bulunmuştur. Videolaringoskobun çocuklarda glottisin görüntülenmesinde ileri bir düzey sağladığını, bununla birlikte entübasyon için daha uzun zaman gerektiğini, entübasyon başarısını ise etkilemediğini vurgulamışlardır. Maruyama ve ark. ise farklı olarak 13 elektif cerrahi planlanan hastada, VL ve Macintosh blade'li laringoskop ile yapılan entübasyonlarda entübasyon sürelerini karşılaştırdıklarında, iki laringoskop arasında entübasyon süreleri açısından anlamlı fark bulamamışlardır (Maruyama ve ark., 2008). Yapılan çalışmaların sonuçları değişkenlik göstermekle beraber çoğunda VL ile entübasyon için gereken sürenin uzadığ 1 görülmektedir.

\section{Videolaringoskopinin hemodinamiye olan etkisi}

Literatürde VL'nin hemodinamiye olan etkisini inceleyen az sayıda literatüre rastlanmıştır. Xue ve ark. elektif plastik cerrahi planlanan 57 hastada, VL ve Macintosh blade'li direkt laringoskopi ile orotrakeal entübasyona hemodinamik yanıtı araştırmışlar ve iki grup arasında anlamlı farklılık bulamamışlardır (Xue ve ark., 2007). Ancak VL grubu'nda entübasyon sonrası kalp hızı, bazal değerin \%20'den fazla üzerine çıkmış ve 4 dakika boyunca devam etmiştir. Macintosh Grubu'nda da taşikardi yanıtı olmuş fakat 1 dakikada sona ermiştir. Sonuç olarak zor entübasyonlarda alternatif olduğu düşünülen VL için, zorluk derecesi daha yüksek olan entübasyonlarda hemodinamik yanıtın ve bu yanıtın ne kadar sürdüğünün araştırılmasının daha farklı sonuçlar gösterebileceği vurgulanmıştır. Jones ve ark. da genel anestezi altında nazal entübasyon planlanan 70 hastada VL ile Macintosh blade'li larigoskopu karşılaştırmışlar, entübasyon sonrası laringoskopiye bağlı hemodinamik yanıtın iki grupta eşit olduğunu bulmuşlardır (Jones ve ark., 2008). Nishikawa ve ark. yaptıkları çalışmada VL ile Macintosh blade'li laringoskopu hemodinami ve bispectral index (BIS) değişimi açısından değerlendirmişler, Macintosh Grubu'nda sistolik kan basıncı ve kalp hızını anlamlı derecede yüksek bulmuşlardır (Nishikawa ve ark., 2009). Hemodinamik yanıtların çalışmalardaki sonuçlar1; özellikle zor entübasyonlarda alternatif olduğu düşünülen VL için zor entübasyonlarda hemodinamik yanıtın araştırılması ve bu hemodinamik yanıtın ne kadar sürdüğünün takip edilmesi yanında anestezi düzeyinin derinliği ve uygulayıc1nın deneyimli olması gibi nedenlerle farklılıklar gösterebileceğini düşündürmektedir.

\section{Videolaringoskopiye bağlı komplikasyonlar}

Barak ve ark., genel anestezi planlanan 170 hastalık çalışmalarında VL ile Machintosh blade'li laringoskobu komplikasyonlar açısından karşılaştırmışlar, entübasyon esnasında yumuşak damak yaralanması ve kanamayı Macintosh grubu'nda anlamlı olarak daha fazla görmüşlerdir (Barak ve ark., 2007). Bunu da VL'nin kullanım kolaylığı ve deneyimli uygulayıcı nedenleri ile açıklamışlardır. Jones ve ark.' da genel anestezi altında nazal entübasyon planlanan 70 hastada VL ile Macintosh blade'li laringoskobu karşılaştırmışlar, orta ve ciddi postoperatif boğaz ağrısını, VL Grubu'nda anlamlı derecede daha az bulmuşlardır (Jones ve ark., 2008). Laringoskopiye bağlı kanama açısından ise iki grup arasında anlamlı fark bulamamışlardır. Maassen ve ark. elektif laparoskopik kolesistektomi planlanan 49 yaşında bayan hastanın preoperatif muayenesinde; dişler arası mesafe 2,9 cm, mallampati grade IV, tiromental mesafe $5,5 \mathrm{~cm}$ tespit etmişlerdir (Maasen ve ark., 2009). Maxiller bölgedeki dişler üzerine, entübasyon esnasında laringoskopun uyguladığı basıncı ölçebilen bir sensör yerleştirmişlerdir. Anestezi indüksiyonu sonrası, önce Macintosh blade'li laringoskop ile entübasyonu denemişler fakat başarı sağlayamamışlar, VL ile entübasyonu gerçekleştirmişlerdir. Sonuçta VL ile daha kolay bir entübasyon sağladıkları ve dişler üzerine olan basıncın daha az 
olduğu kanısına varmışlardır. Bu çalışmalarda VL ile daha az travma gerçekleştiği iddia edilmiştir. Bunun nedeni, uygulama esnasında VL blade'in ağız içine orta hattan girmesi ve kolay görüntü elde edilmesi, çene ve yumuşak damak üzerine daha az güç uygulanması ile ilgili olabilir.

\section{Sonuc}

Öncelikle unutulmamalıdır ki yeni bir laringoskopun ya da VL rolü Macintosh blade ile zor hatta imkansiz olan entübasyonda daha iyi bir performans olmalıdır. Yeni entübasyon cihazlarının etkinliği hakkındaki mevcut bilimsel kanıtları inceleyen bir çalı̧̧mada gerçekten zor entübe olan hasta say1sının azlığı ve seçilen grubun yüksek heterojenitesi nedeniyle toplanan verilerin çoğunun yetersiz olduğu gösterilmiştir (Mihai ve ark., 2008). Bu konuyla ilgili kanıta dayalı çalışmaların çok sınırlı olduğu görülmektedir.

Videolaringoskopik entübasyonları değerlendiren çalışmalar için vurgulanması gereken diğer bir önemli nokta uygulamanın nihai sonucu olarak laringoskoplar arasındaki görüntünün değişimini göz önünde bulundurmuş olmalarıdır. Daha önceki çalışmalarda C-L sınıflaması ve bazı durumlarda da glottik açılmanın yüzdesi glottik görüş skoru olarak kabul edilmiştir (Cormack ve Lehane, 1984; Levitan ve ark., 1998). C-L siniflamas1 1984 'de tanitıldıktan sonra klinik uygulamalarda bir standart olarak kabul edilmesi için modifiye edildi (Yentis ve Lee, 1998; Petrini ve ark., 2005). Videola- ringoskopiler kullanıma girdikten sonra laringoskopik C-L sınıflaması ile videolaringoskopik görüntüyü karşılaştıran yaklaşımın zayıf noktası dışardan gözlemle elde ettiğimiz bir görüntü ile orofarengeal alanda larigoskopun ucuna yerleştirilmiş bir video-kameradan elde edilmiş görüntüleri karş1laştırmaktır. Her iki yöntemde aslında görüş açısı ve görüş doğrultusu tamamen farklıdır. Ayrıca VL daha iyi bir anatomik görüş yaratmaz ancak anatomik yapıların daha iyi bir görüntüsünü mümkün kılar (Byhahn ve ark., 2010). Görüntü hangi yöntemle elde edilmiş olursa olsun başarılı entübasyon oranından ziyade görüntü değişikliklerini karşılaştırmak yeni cihazların doğru sonuçlarına karşı önyargılara sebep olacağ açıktır.

Sonuç olarak VL ile zor entübasyon düşünülen hastalarda daha iyi orofaringeal ve glottik görüntü elde edilmesine rağmen entübasyon başarısı üzerine avantajı bulunmamış, ayrıca VL ile entübasyon süresinin de uzadığı görülmüştür. Zor entübasyon beklenen hastalarda VL ile geleneksel laringoskoplara herhangi bir üstünlük sağlanamamıştır. Anestezistler için asıl amaç başarılı bir görüş sağlamak değil, başarılı bir entübasyon yapmak ve havayolunu en kısa sürede güvence altına almaktır. Yeni laringoskop ya da videolaringoskopların primer rolü konvansiyonel yöntemlerle zor hatta olanaksız olan entübasyonda daha iyi bir performans elde etmek olmalıdır. Bu cihazların klinik rolü zor hava yolu çalışmaları ile desteklenmeyi beklemektedir.

\section{KAYNAKLAR}

Armstrong, J., John, J., Karsli, C., 2010. A comparison between the GlideScope Video Laryngoscope and direct laryngoscope in paediatric with difficult airways - a pilot study. Anaesth. 65, 353-357.

Barak, M., Philipchuck, P., Abecassis, P., Katz, Y., 2007. A comparison of the Truview ${ }^{\circledR}$ blade with the Macintosh blade in adult patients. Anaesth. 62, 827-831.

Bensghir, M., Alaoui, H., Azendour, H., Drissi, M., Elwali, A., Meziane, M., Lalaoui, J.S., Akhaddar, A., Kamili, N.D., 2010 Faster double- 1umen tube intubation with the videolaryngoscope than with a standard laryngoscope. Can J. Anaesth. 57, 980-984.

Burkle, C.M., Zepeda, F.A., Bacon, D.R., Rose, SH., 2004. A historical perspective on the use of the laryngoscope as a tool in anaesthesiol ogy. Anesth. 100,1003-1006.

Byhahn, C., Iber, T., Zacharowski, K., Schalk, R., Meininger, D., 2010. Tracheal intubation using the mobile C-MAC Video Laryngoscope or direct laryngoscopy for patients with a simulated difficult airway. Minerva Anestesiol. 76, 577-583.

Cavus, E., Kieckhaefer, J., Doerges, V., Moeller, T., Thee, C., Wagner, K., 2010. The C-MAC videolaryngoscope: first experiences with a new device for videolaryngoscopy-guided intubation. Anesth, Analg. 110, 473-477.

Cooper, R.M., 2004. Laryngoscopy - its past and future. Can J. Anesth. 51,R1-R5.

Cormack, R.S., Lehane, J., 1984. Difficult tracheal intubation in obstetrics anaesthesia. Anaesthesia. 39, 1105-1111.

Dhonneur, G., Abdi, W., Ndoko, S.K., Amathieu, R., Risk, N., El Housseini, L., Polliand, C., Champault, G., Combes, X., Tual, L., 2009. Videoassisted versus conventional tracheal intubation in morbidly obese patients. Obes. Surg. 19,1096-1101

Enomoto, T., Asai, T., Arai, T., Kamishima, K., Okuda, Y., 2008. Pentax-AWS, a new videolaryngoscope, is more effective than the Macintosh laryngoscope for tracheal intubation in patients with restricted neck movements Br. J. Anaesth. 100, 544-548.

Hackell, R.,. Held, L., Stricker, P., Fladjoe, J.E., 2009. Management of the difficult infant airway with the Storz Video Laryngoscope: a case series. Anesth. Analg. 109,763-766.

Hagberg, C.A, Vogt-Harenkamp, C.C, Iannucci, D.G., 2007. Successful airway management of a patient with a known difficult airway with the Direct Coupler Interface Video Laryngoscope. J. Clin. Anesth. 19, 629-631.

Iacovidou, N., Bassiakou, E., Stroumpoulis, K., Koudouna, E., Aroni, F., Papalois, A., Xanthos, T., 2010. Conventional Direct Laryngoscopy versus Videolaryngoscopy with the GlideScope ${ }^{\circledR}$ : A Neonatal Manikin Study with Inexperienced Intubators. Am. J. Perinatol. Sep 8. [Epub ahead of print]

Jacob, A.K., Kopp, S.L., Bacon, D.R., Smith, H.M., 2009. The History of Anesthesia. In: Barash PG, Cullen BF, Stoelting RK, editors. Clin. Anesth. 6th Ed. Philadelphia: Lippincott Williams \& Wilkins, 3-26.

Jephcott, A., 1984. The Macintosh laryngoscope. A historical note on its clinical and commercial development. Anaesthesia. 39, 474-479.

Jones, P.M., Armstrong, P.M., Cherry, R.A., Harle, C.C., Hoogstra, J., 2008. A comparison of GlideScope videolaryngoscopy to direct laryngoscopy for nasotracheal intubation Anesth. Analg. 107, 144-148.

Kaplan, M.B., Ward, D.S., Berci, G., 2002. A new video laryngoscope-an aid to intubation and teaching. J. Clin. Anesth. 14, 620-626.

Kaplan, M.B., Ward, D., Hagberg, C.A., Berci, G., Hagiike, M., 2006. Seeing is believing: the importance of video laryngoscopy in teaching and in managing the difficult airway. Surg. Endosc. 20,479-483.

Kaplan, M.B, Ward, D., Berc,i G., 2002. Video techniques in thoracic anesthesia. Surg. Anesth. 21, 204-210.

Keaveny, J.P., Knell, P.J., 1988. Intubation under induction doses of propofol. Anaesthesia. 43, 80-81.

Levitan, R.M., Ochroch, E.A., Kush, S., Shofer, F.S., Hollander, J.E. 1998. Assessment of airway visualization: validation of the Percentage Of Glottic Opening (POGO) Scale. Acad. Emerg. Med. 5, 919-923. 
Maassen, R., Lee, R., Van Zundert, A., Cooper R., 2009. The videolaryngoscope is less traumatic than the classic laryngoscope for a difficult airway in an obese patient. J. Anesth. 23, 445-448.

Macintosh, R.R., 1943. A new laryngoscope. Lancet. 241, 205.

Macnair, D., Baraclough, D., Wilson, G., Bloch, M., Engelhardt, T., 2009. Pediatric airway management: comparing the Berci-Kaplan Video Laryngoscope with direct laryngoscopy. Paediatr. Anaesth. 19, 577-580.

Malik, M.A., Maharaj, C.H., Harte, B.H., Laffey, J.G., 2008. Comparison of Macintosh, Truview EVO', GlideScope and Airwayscope laryngoscope use in patients with cervical spine immobilization. Br. J. Anaesth. 101, 723-730.

Mallick, A., Klein, H., Moss, E., 1996. Prevention of cardiovascular response to tracheal intubation. Br. J. Anaesth. 77, 296-297.

Maruyama, K.,Yamada. T., Kawakami, R., Hara, K., 2008. Randomized cross-over comparison of cervical-spine motion with the AirWay Scope or Macintosh laryngoscope with in-line stabilization: a video-fluoroscopic study. Br. J. Anaesth. 101, 563-567.

Merli, G., 2010. Videolaryngoscopy: is it only a change of view? Minerva Anestesiol. 76, 569-571.

Miceli, L., Cecconi, M., Tripi, G., Zauli, M., Della, Rocca, G., 2008. Evaluation of new laryngoscope blade for tracheal intubation, Truview EVO2: a manikin study Eur. J. Anaesth. 25, 446-449

Mihai, R., Blair, E., Kay, H., Cook, TM., 2008. A quantitative review and meta-analysis of performance of non-standard laryngoscopes and rigid fibreoptic intubation aids. Anaesth. 63, 745-760.

Narang, A.T., Oldeg, P.F., Medzon, R., Mahmood, A.R., Spector, J.A., Robinett, D.A., 2009. Comparison of intubation success of video laryngoscopy versus direct laryngoscopy in the difficult airway using high-fidelity simulation. Simul. Healthc. 4, 160-165.

Nishikawa, K., Matsuoka, H., Saito, S., 2009. Tracheal intubation with the Pentax-AWS reduces changes of hemodynamic responses and bispectral index scores compared with the Macintosh laryngoscope. J. Neurosurg. Anesth. 21, 292-296.

Merli, G., Guarino, A., Della Rocca, G., Frova, G., Petrini, F., Sorbello, M., Coccia, C., 2005. Recommendations for airway control and dif fi cult airway management. Minerva Anestesiol. 71, 617-657.

Rodriguez-Nunez, A., Oulego-Erroz, I., Perez-Gay, L., Cortinas-Diaz, J., 2010. Comparison of the GlideScope Videolaryngoscope to the standard macintosh for intubation by pediatric residents in simulated child airway scenarios. Pediatr. Emerg. Care. 26, 726-729.

Shimada, M., Hirabayashi, Y., Seo, N., 2010. [Nasotracheal intubation using GlideScope videolaryngoscope or Macintosh laryngoscope by novice laryngoscopists]. Masui. 59, 1318-1320

Stone, D.J., Gal, T.J., 2000. Airway Management. In Miller RD ed. Anesthesia. 5th ed. Churchill Livingstone NewYork, 39, 1444-1445.

Stroumpoulis, K., Pagoulatou, A., Violari, M., Ikonomou, I., 2009. Videolaryngoscopy in the management of the difficult airway: a comparison with the Macintosh blade. Eur. J. Anaesth. 26, 218-222.

Sun, D.A., Warriner, C.B., Parsons, D.G., Klein, R., Umedaly, H.S., Moult, M., 2005. The GlideScope Video Laryngoscope: randomized clinical trial in 200 patients. Br. J. Anaesth. 94, 381-384.

Van Zundert, A., Maassen, R., Lee, R., Willems, R., Timmerman, M., Siemonsma, M., Buise, M., Wiepking, M., 2009. A Macintosh laryngoscope blade for videolaryngoscopy reduces stylet use in patients with normal airways. Anesth. Analg. 109, 825-831.

Vlatten, A., Aucoin, S., Litz, S., Macmanus, B., Soder, C., 2009. A comparison of the STORZ video laryngoscope and standard direct laryngoscopy for intubation in the Pediatric airway--a randomized clinical trial. Paediatr. Anaesth. 19, 1102-1107.

Xue, FS, Zhang, GH, Li, XY, Sun, HT, Li, P, Li, CW, Liu, KP., 2007. Comparison of hemodynamic responses to orotracheal intubation with the GlideScope videolaryngoscope and the Macintosh direct laryngoscope. J. Clin. Anesth.19, 245-250.

Yentis, S.M., Lee, D.J.H., 1998. Evaluation of an improved scoring System for the grading of direct laryngoscopy. Anaesthesia. 53, $1041-1044$. 